\title{
Increased apoptosis and decreased proliferation of colonic epithelium in dextran sulfate sodium-induced colitis in mice
}

\author{
YOSHIO ARAKI ${ }^{1}$, KEN-ICHI MUKAISYO ${ }^{1}$, HIROYUKI SUGIHARA ${ }^{1}$, \\ YOSHIHIDE FUJIYAMA ${ }^{2}$ and TAKANORI HATTORI ${ }^{1}$ \\ ${ }^{1}$ Department of Pathology and ${ }^{2}$ Department of Internal Medicine, Shiga University \\ of Medical Science, Seta Tsukinowa, Otsu, Shiga 520-2192, Japan
}

Received January 7, 2010; Accepted March 29, 2010

DOI: $10.3892 /$ or_00000932

\begin{abstract}
The pathogenic mechanisms responsible for inflammatory bowel disease, especially ulcerative colitis (UC), are poorly understood. In animal models, the oral administration of dextran sulfate sodium (DSS) induces colitis, which exhibits several clinical and histological features similar to UC. In addition, the longstanding administration of DSS also induces colon cancer. However, the pathogenic factors responsible for DSS-induced colitis and the subsequent colon cancer also remain unclear. In particular, there are only limited data concerning colonic epithelia cell apoptosis and proliferation in DSS-induced colitis. Therefore, we investigated the relationships between these factors. Colitis was induced in BALB/cA Jcl mice by 8 days of oral administration of standard diets containing $5 \%$ (w/w of diet) DSS. The control mice received the standard diets only. Morphological changes in the colonic mucosa were evaluated and scored by light microscopy. Apoptosis was studied by the TUNEL assay, and cell proliferation by Ki-67 immunoreactivity. The macroscopic findings showed the most severe inflammation in the distal colon. Epithelial apoptosis increased $\sim 5$-fold after DSS administration as compared to the controls. On the other hand, the mitotic cells decreased about half-fold as compared to the controls. Ki-67 immunohistochemistry showed that cells with cell cycle arrest at the $G_{0}$ stage in the crypt increased $\sim 2$-fold as compared to the controls. In conclusion, the increased apoptosis and decreased proliferation might lead to a breakdown of the epithelial barrier function, and thus facilitate the mucosal invasion of intraluminal microorganisms in DSS-induced colitis.
\end{abstract}

Correspondence to: Dr Yoshio Araki, 6-13-20 Aoyama, Otsu, Shiga 520-2101, Japan

E-mail: yir0828@belle.shiga-med.ac.jp

Key words: dextran sulfate sodium-induced colitis, apoptosis, proliferation, cell cycle, $\mathrm{G}_{0}$ arrest

\section{Introduction}

The etiology of inflammatory bowel diseases (IBD), ulcerative colitis (UC) and Crohn's disease (CD) still remain unknown. Recent studies have identified interactions between genetic, immunologic, environmental factors and the intestinal microflora in the pathogenesis of IBD (1). On the other hand, it has been established that colorectal cancer can develop as a complication of longstanding colitis $(2,3)$. Therefore, to clarify the mechanisms responsible for IBD and cancer development, and their prevention and treatment, a variety of experimental models for IBD has been developed, including a spontaneous colitis model, induced colitis models, as well as transgenic and knockout colitis models $(4,5)$.

Dextran sulfate sodium (DSS) has been used as one model to induce experimental colitis and colon cancer (6). DSSinduced colitis is favored because of the high reproducibility of the colitis lesions, and because these lesions are induced mainly in the left colon in a fashion similar to human UC (6). Therefore, DSS is widely-used in investigations on the pathogenesis of UC and colon cancer. DSS is a heparin-like sulfated polysaccharide consisting of anhydro-D-glucose $(\alpha-1,6$-glucosidic link) and sulfate. This sulfated polysaccharide contains $\sim 17 \%$ sulfur, with up to three sulfates per glucose molecule (Fig. 1) (7).

With respect to the pathogenic factors in this colitis model, our previous studies have postulated the importance of various factors such as the local involvement of reactive oxygen species $(8,9)$, short chain fatty acids (SCFA) (10), and cell cycle arrest observed in vitro (11). In addition, even a certain dietary fiber can alter the intestinal microflora, produce short chain fatty acids, subsequently colitis improved in human and DSS-induced colitis (12-15). Even probiotics have been reported to have therapeutic effects for both diseases (16). However, the precise etiology of this colitis and colon cancer also remains unclear.

A disruption in the balance between epithelial cell apoptosis and proliferation could be implicated in both colitis and colonic cancer $(17,18)$. One form of epithelial cell injury in the inflamed colonic mucosa of UC has been reported to involve the apoptosis of these cells (19-21). A breakdown of the 
epithelial barrier in UC may facilitate the invasion of intestinal microorganisms, potentially leading to chronic inflammation of the colonic mucosa. The increased colonic epithelial cell proliferation that occurs in UC patients correlates with the increased degree of dysplasia and cancer risk in these patients (22-24).

In DSS colitis, however, there are only limited data concerning colonic epithelia cell apoptosis and proliferation (25-28). Therefore, the aim of our study was to gain insight into the mechanisms of DSS colitis, especially focusing on the process of apoptosis and proliferation of the colonic epithelium.

\section{Materials and methods}

Chemicals. DSS (Mr 5000, total sulfur 15.0-20.0\%) was obtained from Wako Pure Chemical (Osaka, Japan).

Animals. Specific pathogen-free male BALB/cA Jcl mouse, 6 weeks old, were purchased from Nippon Clea Inc. (Tokyo, Japan). They were housed in a room with controlled temperature $\left(20-22^{\circ} \mathrm{C}\right)$, humidity $(50-60 \%)$ and a preset lightdark cycle (12 h:12 h). The experimental protocol was approved by the Animal Care and Use Committee of the Shiga University of Medical Science.

Mouse DSS-induced colitis. The mice were allowed standard rodent powder food (MF, Oriental Yeast Co., Ltd, Tokyo, Japan) and drinking water ad libitum. At the beginning of the experiment, the mice were fed MF containing 5\% (w/w of diet) DSS for 8 days to compare the colonic damages $(n=5)$. Control mouse received MF only. During the experimental period, food intake and body weight were measured every other day. On the final day of the experiment, the mice were anesthetized with an intraperitoneal injection of pentobarbital sodium $(40 \mathrm{mg} / \mathrm{kg}$ ) and were sacrificed by cervical dislocation. After a laparotomy was performed, the large intestine was resected, cut along the anti-mesenteric border, and irrigated with chilled saline. A specimen was removed, frozen, and cut into 5- $\mu \mathrm{m}$ sections. The sections was stained with hematoxylin and eosin (H\&E) and observed under a usual microscope. The mucosal damage was determined according to a previously described method (29).

Briefly, the following three parameters were used: surface epithelium loss, crypt destruction and inflammatory cell infiltration to the mucosa. A score of 0-4 was assigned to each of the three parameters according to the extent and severity of change: 0 , no change; 1 , localized and mild; 2 , localized and moderate; 3 , extensive and moderate; 4 , extensive and severe. The sum of the scores of the three parameters represented the mucosal damage score in each animal. In addition, we observed the cells with mitosis in the sample stained with H\&E. To quantify this mitosis, we calculated randomly the ratio of the cell count with mitosis to total cell count in the crypt. A distal colonic mucosa was counted for each mouse. In addition, we observed mitotic cells in samples stained with H\&E. To quantify this mitosis, we randomly calculated the ratio of the counts of cells undergoing mitosis to total cell count in the crypt. The distal colonic mucosa was counted for each mouse.

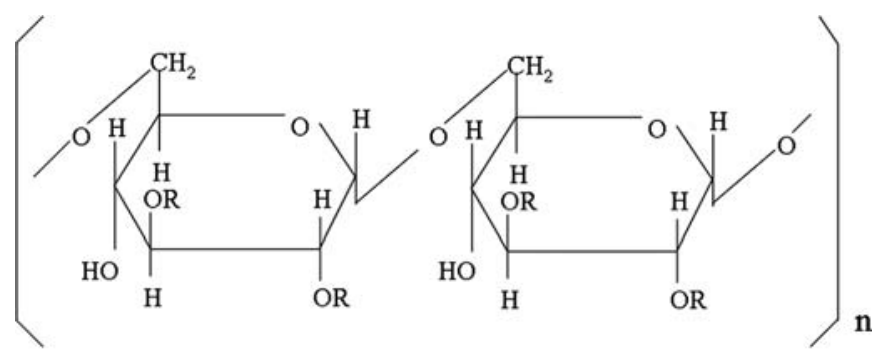

R: $\mathrm{SO}_{3} \mathrm{Na}$ or $\mathrm{H}$

Figure 1. Structure of dextran sulfate sodium (DSS). DSS is a sulfated polysaccharide consisting of anhydro-D-glucose ( $\alpha$-1,6-glucosidic link) and sulfate.

A

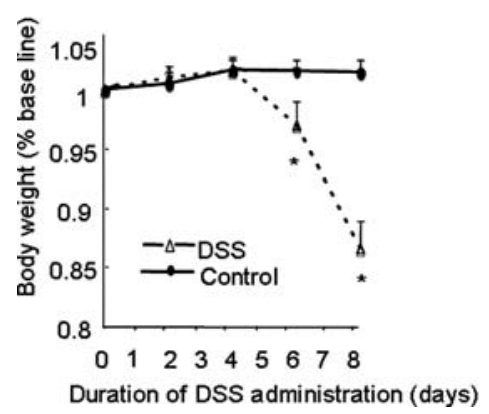

Figure 2. Body weight loss and mucosal damage in DSS-induced colitis mice. (A) Body weight loss in control and DSS-induced colitis mice. (B) The mucosal damage was quantified by a scoring system (29) in the control and DSS-induced colitis mice. All values are expressed as means \pm SEM. ${ }^{*} \mathrm{P}<0.05$.

Immunochemistry. Frozen samples were treated with $20 \mu \mathrm{g} / \mathrm{ml}$ proteinase $\mathrm{K}$ in $10 \mathrm{mM}$ Tris- $\mathrm{HCl}(\mathrm{pH} 8)$ for $20 \mathrm{~min}$ at room temperature, and then rinsed with Tris-buffered saline (1X TBS, $20 \mathrm{mM}$ Tris, pH 7.6, $140 \mathrm{mM} \mathrm{NaCl}$ ). For immunostaining, a TdT-FragEL ${ }^{\mathrm{TM}}$ DNA Fragmentation detection kit (Calbiochem, USA) and an anti-mouse Ki-67 antibody (Dako Cytomation, Denmark) were used according to the manufacturer's protocol to analyze apoptosis and the cell cycle status, respectively. The specimens were finally counter-stained with a methyl green solution. To quantify TdT positive cells, we randomly calculated the TdT positive cell count under a magnification of $x 400$ using a Malassez grid. The results were standardized as the number of TdT positive cells/ $1.5 \mathrm{mmx} 1.5 \mathrm{~mm}$ of sliced mucosa. To quantify anti-Ki-67 positive cells, we also calculated the ratio of anti-Ki-67 positive cells to the total cell count in the crypt. In both staining methods, the distal colonic mucosa was counted for each mouse.

Statistical analysis. The results are presented as means \pm SEM. The variance was analyzed by the F test. Subsequently, Student's t-test for unpaired values was performed to compare the means of normally distributed data. The MannWhitney $\mathrm{U}$ test was also performed to compare the means 

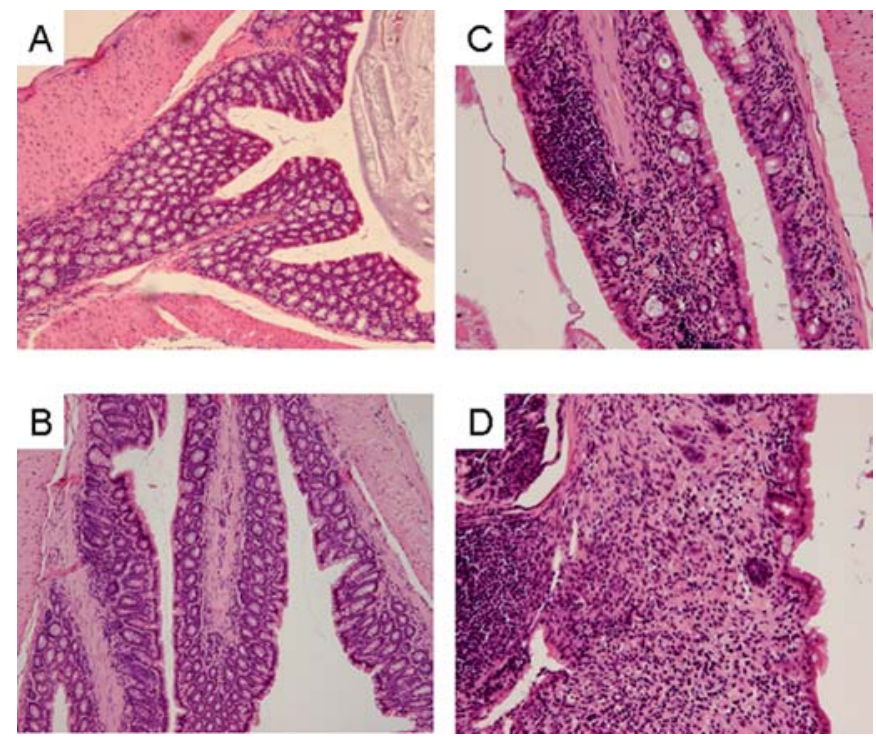

Figure 3. Microscopic findings in DSS-induced colitis mice. (A and B) H\&E staining of the colon in control mice. (C and D) H\&E staining of the colon in DSS-induced colitis mice. Magnification x100.
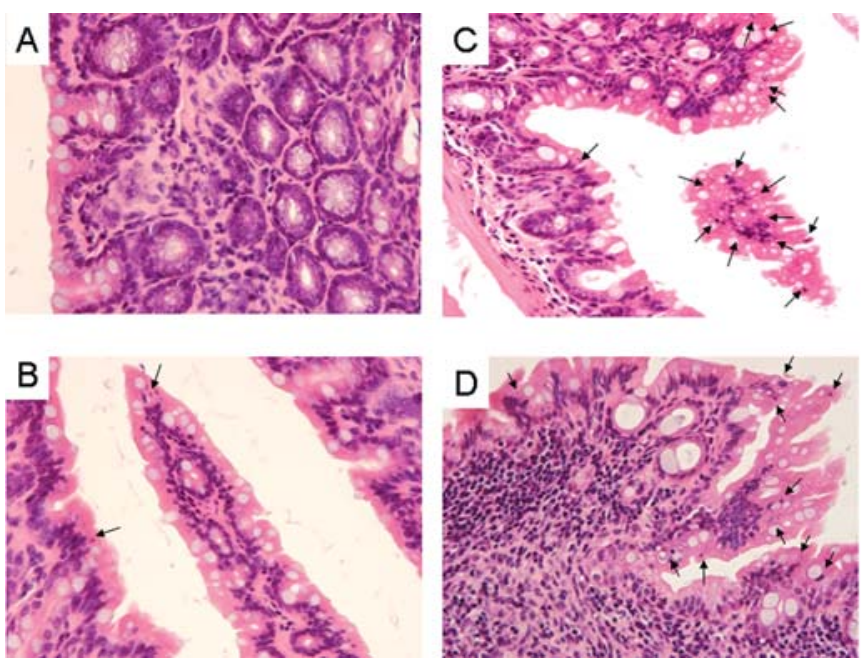

Figure 4. Apoptosis in the colonic epithelium of DSS-induced colitis mice. (A and B) Microscopic findings of the control colons. There were a few apoptotic bodies, especially at the top of the billi (arrow). (C and D) Microscopic findings of the DSS-induced colitis mice. There were more apoptotic bodies recognized. Magnification x200, H\&E staining.

of non-parametric or abnormally distributed data. Differences were regarded as statistically significant at $\mathrm{P}<0.05$.

\section{Results}

Mouse DSS-induced colitis. After the oral administration of DSS, diarrhea occurred on days 3-4. The activity of the mice fed DSS gradually weakened, and simultaneously their oral uptake gradually decreased $(4.6 \pm 0.2 \mathrm{~g} /$ mouse in the control mice and $5.2 \pm 0.3 \mathrm{~g} /$ mouse in the mice fed DSS at the beginning, $5.2 \pm 0.3 \mathrm{~g} /$ mouse in the control mice and $3.9 \pm 0.2 \mathrm{~g} /$ mouse in the mice fed DSS on day 4 , and $5.3 \pm 0.3 \mathrm{~g} / \mathrm{mouse}$ in the control mice and $2.9 \pm 0.2 \mathrm{~g} /$ mouse in the mice fed DSS on day 8 ). The body weight loss in those mice fed DSS was
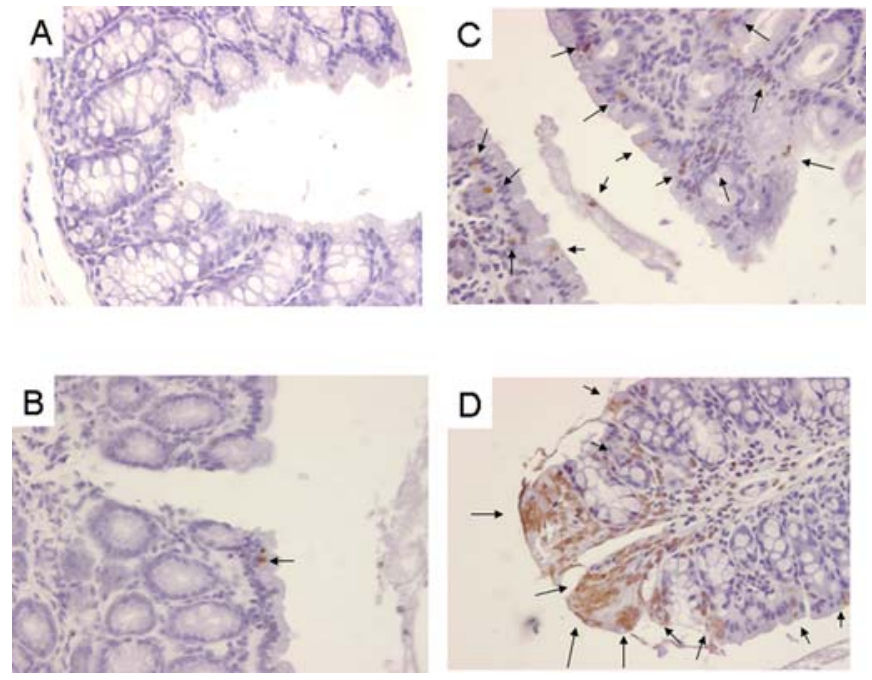

Figure 5. TdT positive apoptosis in the colonic epithelium of DSS-induced colitis mice. (A and B) Microscopic findings of the control colons. There were a few TdT positive cells in the epithelium (arrow). (C and D) Microscopic findings of the DSS-induced colitis mice. There were more TdT positive cells recognized. Magnification x200, TdT staining.

evident (Fig. 2A). The differences between the control mice and the mice fed DSS were statistically significant on days 6 and 8.

Macroscopic examination of the colon revealed hyperemia, erosion and occasional tiny blood clots in the distal colon. Fig. 3 shows the microscopic findings of the distal colon in control and DSS-induced colitis mice. Using H\&E staining, there was obvious evidence of inflammatory cell infiltration into the mucosa and submucosa in the distal portions on day 8 . Entire crypt loss, surface epithelial loss and mucosal edema were also evident as compared to the control mice. The mucosal damage was quantified by a scoring system shown in Fig. 2B. The difference between the control mice and those fed DSS was statistically significant.

Apoptosis. There were a few apoptotic bodies present in the control mice using H\&E staining (Fig. 4A and B). These apoptotic bodies were few, but were clustered at the top of the billi. These apoptotic bodies were more prominent in the mice fed DSS (Fig. 4C and D). Fig. 5 shows the staining using the TUNEL assay [terminal deoxynucleotidyl transferase (TdT), which binds to the exposed 3'-OH ends of the DNA fragments generated in response to apoptotic signals]. In the control mice, there were a few TdT positive cells in the epithelium (Fig. 5A and B). However, these TdT positive cells were more prominent in the mice fed DSS (Fig. 5C and D). We randomly calculated the TdT positive cell count. The administration of DSS significantly increased the TdT positive cells as compared to the control mice (Fig. 6A).

Mitosis. In the control mice, there was sporadic mitosis present in the crypts using H\&E staining (Fig. 7A and B). However, mitoses became fewer in the mice fed DSS (Fig. 7C and D). We calculated the ratio of the mitotic cell count, and the administration of DSS significantly reduced the mitosis ratio as compared to the control mice (Fig. 6B). 

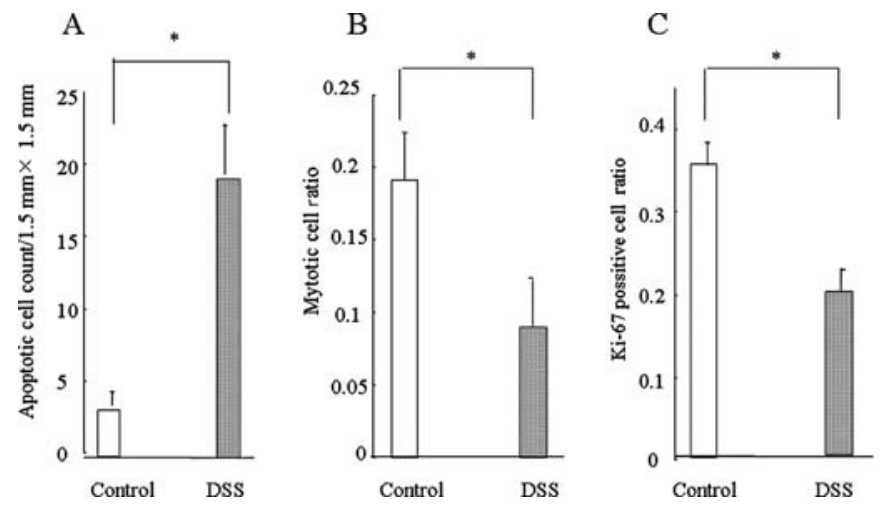

Figure 6. Apoptosis, mitosis and cell cycle state in the colonic crypts of DSS-induced colitis mice. (A) To quantify the apoptotic cells, we randomly calculated the TdT positive cell count under a magnification of $\mathrm{x} 400$ using a Malassez grid. The results were standardized as the number of TdT positive cells/area of $20 \mathrm{~mm}^{2}$ of sliced mucosa. (B) To quantify the mitosis, we calculated the ratio of the crypt count with mitosis to the total crypt cell count. (C) To quantify the cell cycle status, we calculated the ratio of the anti-Ki-67 positive cell count to the total cell count in the crypt. All values are expressed as means \pm SEM. ${ }^{*} \mathrm{P}<0.05$.
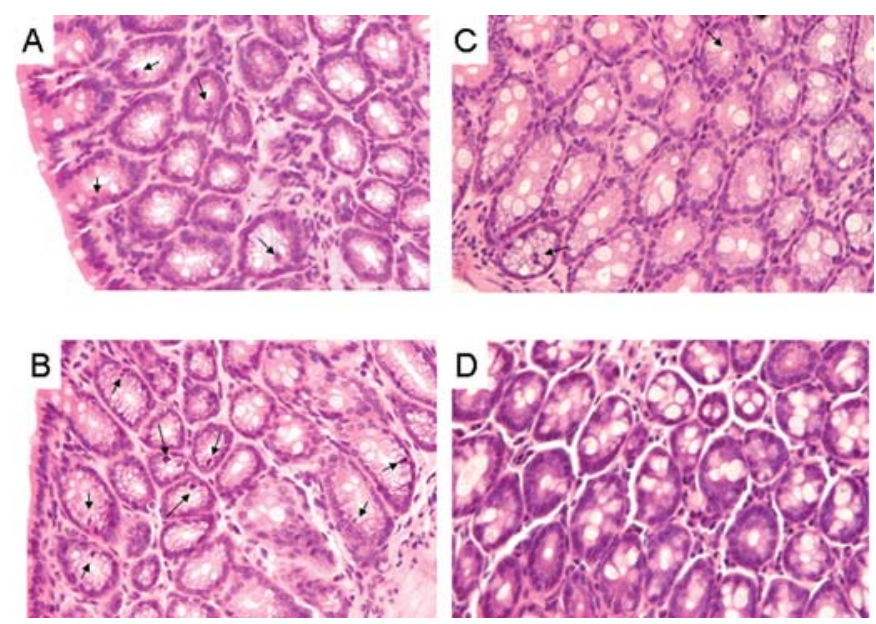

Figure 7. Mitosis in the colonic crypts of DSS-induced colitis mice. (A and B) Microscopic findings of the control colons. There were sporadic mitoses in the crypts (arrow). (C and D) Microscopic findings of the DSS-induced colitis mice. There were fewer mitoses recognized. Magnification x200, H\&E staining.

Cell cycle analysis. We observed the cell cycle status of the epithelium using immunostaining with an anti-mouse Ki-67 antibody, which indicates the activated phases of the cell cycle $\left(\mathrm{G}_{1}, \mathrm{~S}, \mathrm{G}_{2}\right.$, and $\mathrm{M}$ phases $)$. In the control mice, there were some anti-Ki-67 positive cells in the lower part of the crypt (Fig. 8A and B). However, the anti-Ki-67 positive cells were reduced in the mice fed DSS (Fig. 8C and D). We calculated the ratio of the anti-Ki-67 positive cell count, and the administration of DSS significantly reduced the anti-Ki-67 positive cell ratio as compared to the control mice (Fig. 6C). These results suggest that DSS induced cell cycle arrest, especially at the $\mathrm{G}_{0}$ phase, and induced the apoptosis of the colonic epithelial cells.
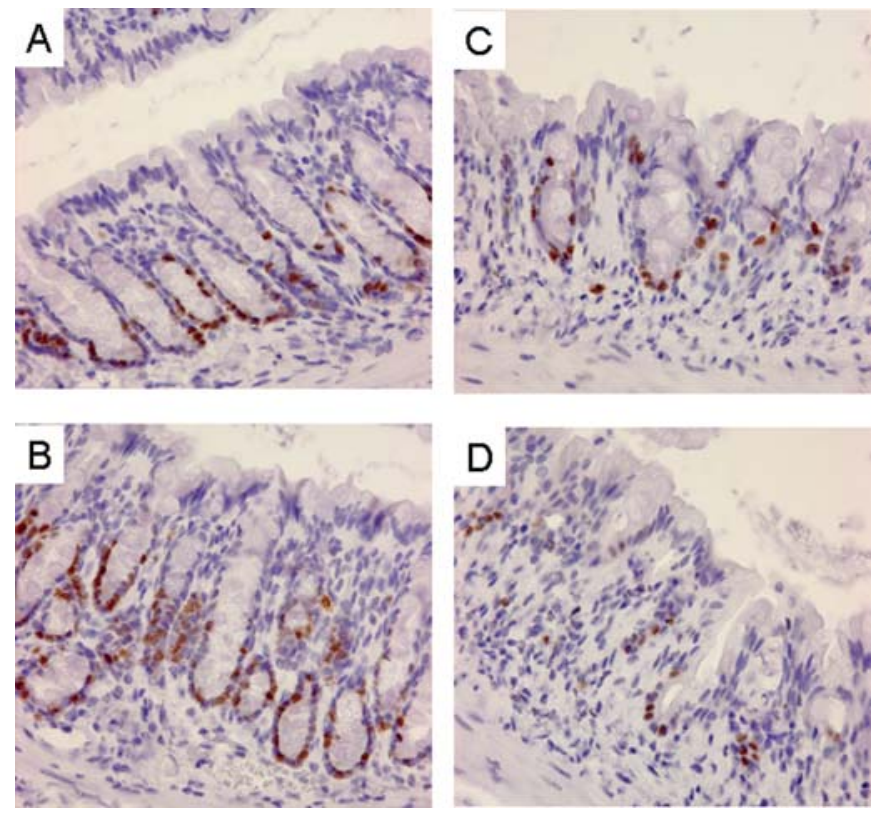

Figure 8. Cell cycle analysis using an anti-Ki-67 antibody in the colonic crypts of DSS-induced colitis mice. (A and B) Microscopic findings of the control colons. There were many anti-Ki-67 positive cells in the lower part of the crypt. (C and D) Microscopic findings of the DSS-induced colitis mice. There were fewer anti-Ki-67 positive cells recognized in the lower parts of the crypts. Magnification x200.

\section{Discussion}

Previous studies reported that repeated cycles of the oral administration of $4 \%$ DSS in rats was able to induce an abnormal increase in the proliferation of colonic epithelial cells (28) or was able to induce an abnormal increase in both the proliferation and apoptosis rates of the colonic epithelial cells (27). In addition, repeated cycles of DSS administration also caused dysplasia and/or cancer as flat lesions or as dysplasia-associated lesions or masses (DALM) (30). However, DSS responds negatively in the Ames test for mutagens (31). Therefore, the neoplastic changes seemed to originate from the mucosal inflammation itself through a recurrenceremission cycle.

In UC, both increased proliferation and increased apoptosis were observed (19-24). This phenomenon was suggested to be due to a recurrence-remission cycle $(31,32)$. This hyperproliferation and abnormal distribution of the replicating cells was considered to be a biomarker of increased susceptibility to colorectal cancer (33), because highly regulated processes are essential for tissue remodeling in tissue repair following injury.

In our study, the oral administration of DSS induced several symptoms including diarrhea and weight loss, and histological changes of the colonic mucosa including inflammation and crypt loss, especially in the distal colon.

In addition, DSS administration certainly induced apoptosis. In particular, DSS administration decreased proliferative cells $\left(-\mathrm{G}_{1}-\mathrm{S}-\mathrm{G}_{2}-\mathrm{M}-\mathrm{G}_{2}-\right.$ ), and increased those on the static phase $\left(\mathrm{G}_{0}\right)$. This phenomenon indicates that DSS arrests the cell cycle far from cell proliferation. Our results are consistent with a previous study which showed that DSS 
decreased the number of proliferating epithelial cells by $\sim 90 \%$ using the bromodeoxyuridine labeling system (26) and our previous in vitro study using Caco-2 cell line (11). Therefore, increased apoptosis and cell arrest might produce subsequent cell proliferation.

In our study, $5 \%$ DSS induced severe colitis for a short period. Diarrhea occurred on days 3-4, and the body weight loss progressed simultaneously. Therefore, it is reasonable that the repair and/or proliferation processes might catch up with the progression of the DSS-induced apoptosis and cell cycle arrest. The increased apoptosis and cell cycle arrest due to DSS administration might lead to a breakdown of the epithelial barrier function at a very early phase of colitis, which might lead to the mucosal invasion of intestinal bacterial and their toxins $(34,35)$. If animals were given repeated cycles of DSS administration, then the colonic epithelium might undergo chronic inflammation, including subsequently increased proliferation. In addition, it is possible that this chronic colitis may lead to an increased incidence of colon cancer.

One of the most important questions is why and/or how DSS can induce apoptosis and the cell arrest of colonic epithelial cells. Since apoptosis generally removes cells with damaged DNA from the epithelium (17), it is recognized that this short-term DSS administration might be related to cell cycle arrest rather than to damaged DNA. However, the precise mechanisms responsible for this apoptosis and cell cycle arrest remain unknown.

In conclusion, both the increased apoptosis and the cell cycle arrest of the colonic epithelial cells were characterized in DSS-induced acute colitis in mice. DSS-induced colitis is a well-characterized model for studying colitis-associated apoptosis and proliferation processes.

\section{References}

1. Papadakis KA and Targan SR: Current theories on the causes of inflammatory bowel disease. Gastroenterol Clin North Am 28: 283-296, 1999.

2. Lewis JD, Deren JJ and Lichtensten GR: Cancer risk in patient with inflammatory bowel diseases. Gastroenterol Clin North Am 28: 459-477, 1999.

3. Pohl C, Hombach A and Kruis W: Chronic inflammatory bowel disease and cancer. Hepatogastroenterology 47: 57-70, 2000.

4. Mayer L: The development of animal models of inflammatory bowel disease. Int Rev Immunol 19: 77-90, 2000.

5. Blumberg RS, Saubermann LJ and Strober W: Animal models of mucosal inflammation and their relation to human inflammatory bowel disease. Curr Opin Immunol 11: 648-656, 1999.

6. Elson CO, Sartor RB, Tennyson GS and Riddell RH: Experimental models of inflammatory bowel disease. Gastroenterology 109: 1344-1367, 1995

7. Ricketts CR: Dextran sulphate- $\alpha$ synthetic analogue of heparin. Biochem J 51: 129-133, 1952.

8. Araki Y, Andoh A and Fujiyama Y: The free radical scavenger edaravone suppresses experimental dextran sulfate sodiuminduced colitis in rats. Int J Mol Med 12: 125-129, 2003.

9. Araki Y, Sugihara H and Hattori T: The free radical scavengers edaravone and tempol suppress experimental dextran sulfate sodium-induced colitis in mice. Int J Mol Med 17: 331-334, 2006.

10. Araki Y, Andoh A, Takizawa J, Takizawa W and Fujiyama Y: Clostridium butyricum, a probiotic derivative, suppresses dextran sulfate sodium-induced experimental colitis in rats. Int J Mol Med 13: 577-580, 2004.

11. Araki Y, Sugihara $\mathrm{H}$ and Hattori T: In vitro effects of dextran sulfate sodium on a Caco-2 cell line and plausible mechanisms for dextran sulfate sodium-induced colitis. Oncol Rep 16: 1357-1362, 2006.
12. Araki Y, Andoh A, Koyama S, Fujiyama Y, Kanauchi O and Bamba T: Effects of germinated barley foodstuff on microflora and short chain fatty acid production in dextran sulfate sodiuminduced colitis in rats. Biosci Biotechnol Biochem 64: 1794-1800, 2000.

13. Araki Y, Fujiyama Y, Andoh A, Koyama S, Kanauchi O and Bamba T: The dietary combination of germinated barley foodstuff plus Clostridium butyricum suppresses the dextran sulfate sodium-induced experimental colitis in rats. Scand J Gastroenterol. 35: 1060-1067, 2000.

14. Araki Y, Andoh A, Fujiyama Y, Kanauchi O, Takenaka K, Higuchi A and Bamba T: Germinated barley foodstuff exhibits different adsorption properties for hydrophilic versus hydrophobic bile acids. Digestion 64: 248-254, 2001.

15. Kanauchi O, Mitsuyama K, Homma T, Takahama K, Fujiyama Y, Andoh A, Araki Y, Suga T, Hibi T, Naganuma M, Asakura H, Nakano H, Shimoyama T, Hida N, Haruma K, Koga H, Sata M, Tomiyasu N, Toyonaga A, Fukuda M, Kojima A and Bamba T: Treatment of ulcerative colitis patients by long-term administration of germinated barley foodstuff: multi-center open trial. Int J Mol Med 12: 701-704, 2003.

16. Foligne B, Dessein R, Marceau M, Poiret S, Chamaillard M, Pot B, Simonet $\mathrm{M}$ and Daniel C: Prevention and treatment of colitis with Lactococcus lactis secreting the immunomodulatory Yersinia LcrV protein. Gastroenterology 133: 862-874, 2007.

17. Jones BA and Gores GJ: Physiology and pathophysiology of apoptosis in epithelial cells of the liver, pancreas, and intestine. Am J Physiol 273: G1174-G1188, 1997.

18. Watson AJ and Pritchard DM: Lesson from genetically engineered animal model. VII. Apopthosis of intestinal epithelium: Lesson from transgenic and knockout mice. Am J Physiol Gastrointest Liver Physiol 278: 1-5, 2000.

19. Iwamoto M, Koji T, Makiyama K, Kobayashi N and Nakane PK: Apoptosis of crypt epithelial cells in ulcerative colitis. J Pathol 180: 152-159, 1996.

20. Strater J, Wellisch I, Riedl S, Walczak H, Koretz K, Tandara A, Krammer PH and Moller P: CD95 (APO-1/fas) mediated apoptosis in colon epithelial cells a possible role in ulcerative colitis. Gastroenterology 113: 160-167, 1997.

21. Iimura M, Nakamura T, Shinozaki S, Iizuka B, Inove Y, Suzuki S and Hayashi N: Bax is downregulated in inflamed colonic mucosa of ulcerative colitis. Gut 47: 228-235, 2000.

22. Serafini EP, Kirk AP and Chambers TJ: Rate and pattern of epithelial cell proliferation in ulcerative colitis. Gut 22: 648-652, 1981.

23. Andersen SN, Rognum TO, Bakka A and Clausen OP: Ki-67: A useful marker for the evaluation of dysplasia in ulcerative colitis. Mol Pathol 51: 327-332, 1998.

24. Arai N, Mitomi H, Ohtani Y, Igarashi M, Kakita A and Okayasu I: Exhanced epithelial cell turnover associated with p53 accumulation and high p21WAF1/CIP1 expression in ulcerative colitis. Mod Pathol 12: 604-611, 1999.

25. Tardieu D, Jaeg JP, Deloly A, Corpet DE, Cadet J and Petit CR: The COX-2 inhibitor nimesulide suppresses superoxide and 8-hydroxy-deoxyguanosine formation, and stimulates apoptosis in mucosa during early colonic inflammation in rats. Carcinogenesis 25: 973-976, 2000

26. Tessner TG, Cohn SM, Schloemann S and Stenson WF: Prostaglandins prevent decreased epithelial cell proliferation associated with dextran sodium sulfate injury in mice. Gastroenterology 115: 874-882, 1998.

27. Vetuschi A, Latella G, Sferra R, Caprilli R and Gaudio E: Increased proliferation and apoptosis of colonic epithelial cells in dextran sulfate sodium-induced colitis in rats. Dig Dis Sci 47: 1447-1457, 2002.

28. Inoue T, Murano M, Kuramoto T, Ishida K, Kawakami K, Abe Y, Morita E, Murano N, Toshina K, Nishikawa T, Maemura K, Shimamoto C, Hirata I, Katsu K and Higuchi K: Increased proliferation of middle to distal colonic cells during colorectal carcinogenesis in experimental murine ulcerative colitis. Oncol Rep 18: 1457-1462, 2007.

29. Oda T: Role of mast cells in dextran sulfate sodium-induced experimental colitis in rats. J Kyoto Pref Univ Med 104: 1069-1082, 1995.

30. Cooper HS, Murthy S, Kido K, Yoshitake H and Flanigan A: Dysplasia and cancer in dextran sulfate sodium mouse colitis model. Relevance to colitis-associated neoplasia in the human: A study of histopathology, $B$ catenin and $p 53$ expression and the role of inflammation. Carcinogenesis 21: 757-768, 2000. 
31. Chiba T: Cell kinetiks of carcinoma originating from rat colitis induced by dextran sulphate sodium. Nippon Shokakibyo Gakkai Zasshi (In Japanese) 90: 774-781, 1993.

32. Okayasu I, Hatakeyama S, Yamada M, Ohkusa T, Inagaki Y and Nakaya R: A novel method in the induction of reliable experimental acute and chronic ulcerative colitis in mice. Gastroenterology 98: 694-702, 1990.

33. Lipkin M: Biomarkers of increased susceptibility to gastrointestinal cancer: New application to studies of cancer prevention on human subjects. Cancer Res 48: 235-245, 1988.
34. Hans W, Scholmerich J, Gross V and Falk W: The role of the resident intestinal flora in acute and chronic dextran sulfate sodium induced colitis in mice. Eur J Gastroenterol Hepatol 12: 267-273, 2000 .

35. Kitajima S, Takuma $\mathrm{S}$ and Morimoto $\mathrm{M}$ : Changes in colonic mucosal permeability in mouse colitis induced with dextran sulfate sodium. Exp Anim 48: 137-143, 1999. 